\title{
The Salmonella typhi melittin resistance gene pqaB affects intracellular growth in PMA- differentiated U937 cells, polymyxin B resistance and lipopolysaccharide
}

\author{
Sarah J. Baker,' John S. Gunn² and Renato Morona' \\ Author for correspondence: Sarah J. Baker. Tel: +61 88303 5827. Fax: +61 883034362. \\ e-mail: sbaker@microb.adelaide.edu.au
}

\begin{abstract}
1 Department of Microbiology and Immunology, University of Adelaide, Adelaide, South Australia, Australia 5005

2 Department of Microbiology, University of Texas Health Science Centre at San Antonio, 7703 Floyd Curl Dr, San Antonio, TX 78284-7758, USA
\end{abstract}

\begin{abstract}
Salmonella typhi is the causative agent of typhoid fever in humans. A cellculture based assay involving the human monocyte macrophage cell line U937 has been developed to examine S. typhi invasion and survival. An S. typhi PhoP- (null) mutant was shown to be restricted in net growth in phorbol myristate acetate (PMA) differentiated U937 (PMA-U937) cells, and an S. typhi Phopc (constitutive) mutant showed a defect in invasion. Neither of the phoPIQ mutants were growth impaired in HeLa cells, however the PhoP' mutant was impaired in invasion. As opposed to what was found for S. typhi, Salmonella typhimurium wild-type, PhoP- and PhoPc mutants grew equally well in PMA-U937 cells, indicating that the PhoP--mediated net growth restriction in the PMA-U937 cells was S. typhi specific. An S. typhi mutation, pqaB::MudJ, recently shown to be a PhoP-activated locus, was shown to have a net growth defect in PMA-U937 cells. Sequencing of the S. typhi pqaB gene revealed it had $98 \%$ identity to the fifth gene in a $S$. typhimurium PmrA/B regulated operon necessary for 4-aminoarabinose lipid A modification and polymyxin B resistance. The pqaB locus was regulated by PmrA/B (whose activity is modulated by PhoP-PhoQ) and the pqaB transposon mutant was sensitive to polymyxin B. The lipopolysaccharides (LPS) of S. typhi and S. typhimurium wildtype, PhoP- and Phopc mutants, were compared by SDS-PAGE and silver staining. Differences in the LPS profile between the two Salmonella species were observed, and shown to be affected differently by the PhoP' mutation. Additionally, the pqaB:: MudJ mutation affected S. typhi LPS. The effects on LPS may have ramifications for the difference between $S$. typhi and $S$. typhimurium infection of hosts.
\end{abstract}

Keywords: virulence, $\mathrm{PhoP} / \mathrm{Q}$ regulon, $p q a / p q r, \mathrm{PmrA} / \mathrm{B}$, polymyxin $\mathrm{B}$

\section{INTRODUCTION}

Salmonella typhi, the causative agent of typhoid fever in humans, remains a significant health problem throughout the world, especially in developing nations. This species is highly host adapted and is non-pathogenic in animals (Miller et al., 1995). An important part of Salmonella pathogenesis is the ability of the bacterium to survive and multiply in macrophages (Fields et al.,

Abbreviations: 4AA, 4-aminoarabinose; GI, growth index; LPS, lipopolysaccharide; PMA, phorbol myristate acetate; PmB, polymyxin B.

The GenBank/EMBL/DDBJ accession number for the sequence reported in this paper is AF0718082.
1986; Buchmeier \& Heffron, 1989). It has been suggested that the adaptation of Salmonellae to a particular host species is related to their relative ability to survive and replicate in the reticulo-endothelial system (Barrow et al., 1994).

Salmonella typhimurium survival in macrophages has been shown to be dependent on the PhoP/Q twocomponent regulatory system, which has been extensively reviewed (Groisman \& Saier, 1990; Miller, 1991; Vescovi et al., 1994). The PhoP/Q regulon both activates and represses numerous unlinked genes in response to environmental signals: extracellular $\mathrm{Mg}^{2+}$ levels and $\mathrm{pH}$ (Garcia Vescovi et al., 1996; Bearson et al., 1998; Soncini \& Groisman, 1996). A large number of PhoP- 
activated genes ( $p a g / p q a)$ and PhoP-repressed genes ( $p r g / p q r)$ have been identified in S. typhimurium, for example genes involved in macrophage survival (pagC) (Pulkkinen et al., 1991), invasion of mammalian cells and protein secretion (prgHIJK) (Behlau \& Miller, 1993; Johnston et al., 1996), phoN, which encodes a non-specific acid phosphatase (Kasahara et al., 1991; Groisman et al., 1992), and $m g t A$ and $m g t C B$ genes encoding high-affinity magnesium transporters (Soncini \& Groisman 1996). PhoP/Q has also been found to regulate genes encoding the $\mathrm{PmrA} / \mathrm{B}$ two-component regulatory system, providing a regulatory cascade which regulates genes including $p m r E / u g d$ (Groisman et al., 1997; Gunn \& Miller, 1996) and the recently identified $p m r F$ operon, which is involved with polymyxin B (PmB) resistance and lipid A modifications (Gunn \& Miller, 1996; Guo et al., 1997; Gunn et al., 1998). PhoP null $\left(\mathrm{PhoP}^{-}\right)$S. typhimurium mutants (in which PhoPrepressed genes are upregulated and PhoP-activated genes downregulated) have been shown to be defective in macrophage survival (Miller et al., 1989), attenuated for virulence in mice (Fields et al., 1989), sensitive to host antimicrobial peptides (Groisman et al., 1992; Selsted et al., 1992; Porter et al., 1997), and recent studies have shown that an S. typhi $\triangle p h o P Q$ mutant is attenuated in humans (Hohmann et al., 1996a, b). This clearly demonstrated that the PhoP-activated genes are involved with $S$. typhi pathogenesis. S. typhimurium PhoP constitutive ( $\mathrm{PhoP}^{\mathrm{c}}$ ) mutants (in which PhoPactivated genes are upregulated and PhoP-repressed genes are downregulated) have been shown to be deficient in invasion of mammalian cells (Behlau et al., 1993; Pegues et al., 1995), formation of spacious phagosomes within professional and non-professional phagocytes (Alpuche-Aranda et al., 1994, 1995), defective for macrophage survival and are attenuated for virulence in mice (Miller \& Mekalanos, 1990). Therefore, it has been suggested that a temporal shift from PhoP-repressed genes to PhoP-activated genes may be necessary for invasion and survival within macrophages.

We have previously isolated and characterized a number of mutants in S. typhi PhoP/Q regulated $p q a / p q r$ genes (Baker et al., 1997); the $p q a A$ and pqaB mutants were found to have increased sensitivity to the antimicrobial peptide melittin. In this work we screened these mutants for defects in invasion and macrophage survival by using PMA- (phorbol myristate acetate) differentiated U937 cells (PMA-U937 cells), which are macrophage-like cells. U937 is a human monocytic suspension cell line (Sundstrom \& Nilsson, 1976), and the cells express many of the normal mononuclear phagocyte characteristics, including adherence, when differentiated by PMA (Harris \& Ralph, 1985; Hass et al., 1989; Minta \& Pambrun, 1995; Pedrinaci et al., 1989). We identified the S. typhi PhoP/Q-regulated $p q a B::$ MudJ fusion mutant as being defective in net growth in the PMA-U937 cells. Cloning and sequence analysis of the $p q a B$ gene showed it to be almost identical to a gene within the $S$. typhimurium PmrA/B-regulated $p m r F$ operon affecting modification of lipid A. Finally, we showed by SDS-
PAGE analysis that PhoP and PhoQ have different effects on the lipopolysaccharide (LPS) of S. typhi and $S$. typhimurium.

\section{METHODS}

Bacterial strains, mammalian cell lines and chemicals. Bacterial strains used in this study are described in Table 1. Bacteria were grown at $37^{\circ} \mathrm{C}$ with aeration in Luria-Bertani broth (LB) (Morona et al., 1995), unless noted otherwise. Bacteria were plated out on Luria Agar (LA) plates consisting of LB containing $1.5 \%(\mathrm{w} / \mathrm{v}$ ) Bacto agar (Difco). Colour indicator plates were X-pho plates (MM or LA with the addition of 5-bromo-4-chloro-3-indolyl phosphate (Boehringer Mannheim) or X-Gal (LA with the addition of 5bromo-4-chloro-3-indolyl- $\beta$-D-galactopyranoside (Boehringer Mannheim) with both X-pho and X-Gal freshly dissolved in dimethyl formamide at a final concentration of $40 \mu \mathrm{g} \mathrm{ml}^{-1}$ ). Tetracycline (Sigma) was used at $10 \mu \mathrm{g} \mathrm{ml}^{-1}$. The U937 monocyte cell line (obtained from Professor L. Ashman, Hanson Cancer Research Centre, Adelaide) was maintained in RPMI-1640 media containing $10 \%(\mathrm{v} / \mathrm{v})$ foetal bovine serum, $1 \%(\mathrm{w} / \mathrm{v})$ glutamine with $100 \mathrm{U}$ penicillin $\mathrm{ml}^{-1}$ and $100 \mu \mathrm{g}$ streptomycin $\mathrm{ml}^{-1}$ (Gibco-BRL) (RPMI maintenance media) at $37^{\circ} \mathrm{C}$ with $5 \% \mathrm{CO}_{2}$. HeLa cells (human epithelial carcinoma cells - ATCC CCL2) were maintained in MEM (Minimal Eagles salt medium) containing $10 \%(\mathrm{v} / \mathrm{v})$ foetal bovine serum, $1 \%(\mathrm{w} / \mathrm{v})$ glutamine with $100 \mathrm{U}$ penicillin $\mathrm{ml}^{-1}$ and $100 \mu \mathrm{g}$ streptomycin $\mathrm{ml}^{\mathbf{1}}$ (Gibco-BRL) (MEM maintenance media). Tissue culture assay medium was the same as the maintenance medium for each cell type but did not contain antibiotics. PMA (Sigma) was dissolved in DMSO and stored at $-20^{\circ} \mathrm{C}$ at $10 \mu \mathrm{g} \mathrm{ml}^{-1}$. Stocks of PmB (Sigma) were freshly made each time by dissolving appropriate amounts of solid in PBS.

Bacterial and tissue cell culture. The PMA-differentiated cell assay was modified from the assay used by Hone et al. (1992). Differentiation of U937 cells with PMA to obtain monocytederived macrophages involved washing U937 cells grown to a high density, and seeding in 24 multi-well plates (Corning, 25820) at approximately $1 \times 10^{6}$ cells per well in RPMI maintenance media containing $6 \mathrm{ng}$ PMA ml-1. Cells were differentiated with PMA for $72 \mathrm{~h}$ before being washed three times with PBS prior to the assay. HeLa cells were grown to semi-confluency and seeded in a 24 well tray. After incubation for $24 \mathrm{~h}$ (cells were now $\sim 1 \times 10^{6}$ cells per well), the cells were washed three times with PBS prior to the assay.

All bacterial strains were grown for $16 \mathrm{~h}$ in $\mathrm{LB}$ at $37^{\circ} \mathrm{C}$ with aeration, subcultured $1 / 20$ into $10 \mathrm{ml} \mathrm{LB}$ and grown for $2.5 \mathrm{~h}$ until bacteria had reached $1 \times 10^{9}$ cells $\mathrm{ml}^{-1}$. Bacteria were then washed and diluted in the appropriate tissue culture media (RPMI or MEM assay media) to add to the tissue culture cells.

Salmonella $\mathrm{PhoP}^{+}, \mathrm{PhoP}^{-}$and $\mathrm{PhoP}^{\mathrm{c}}$ strains can be differentiated on LA + X-pho (Baker et al., 1997). All strains used in the bacterial invasion and survival assays were tested after $24 \mathrm{~h}$ growth on colour-indicator plates; all strains gave correct-coloured colonies, indicating that the mutations were stable throughout the assay.

Bacterial infection of HeLa cells and PMA-U937 cells. After bacteria were added to the HeLa and PMA-U937 cells ( $S$. typhi strains were added at a ratio of 10:1 and S. typhimurium strains at 1:1 bacteria:tissue-culture cells), invasion was allowed to occur for $2 \mathrm{~h}$, the bacteria were removed and the cells washed once with PBS, and the appropriate media containing $0.2 \mathrm{mg}$ gentamicin $\mathrm{ml}^{-1}$ (Gibco-BRL) was added 
Table 1. Escherichia coli and Salmonella strains used in this study

\begin{tabular}{|c|c|c|}
\hline Strain & Characteristics & Source/construction \\
\hline \multicolumn{3}{|c|}{ E. coli $\mathrm{K}-12$} \\
\hline DH5 $\alpha$ & $\begin{array}{l}\mathrm{F}-\phi 80 \text { lacZ } \Delta M 15 \Delta(\text { lacZYA-argF }) \text { supE- } 44 \text { thi-1 } \\
\left.\text { gyrA-96 rec-A1 end-A1 rel-A1 hsd-R17( } \mathrm{r}_{\mathrm{k}}^{-} \mathrm{m}_{\mathrm{k}}^{+}\right)\end{array}$ & BRL \\
\hline RMA292 & $\mathrm{DH} 5 \alpha(\mathrm{pRMSB} 50)$ & This work \\
\hline RMA295 & $\mathrm{DH} 5 \alpha(\mathrm{pRMSB} 53)$ & This work \\
\hline \multicolumn{3}{|c|}{ S. typhimurium } \\
\hline $\mathrm{C} 5$ & Wild-type & Laboratory collection \\
\hline RMA1010 & C5 phoP12, PhoP $^{-}$ & Baker et al. (1997) \\
\hline RMA1024 & $\mathrm{C} 5$ phoP24, PhoPc & Baker et al. (1997) \\
\hline JSG421 & $p m r A:: \operatorname{Tn} 10$ & Gunn \& Miller (1996) \\
\hline \multicolumn{3}{|l|}{ S. typhi } \\
\hline Ty 2 & Wild-type & Hone et al. (1988) \\
\hline RMA1030 & Ty2 phoP12, Phop- & Baker et al. (1997) \\
\hline RMA1090 & Ty2 phoP24, PhoPc & Baker et al. (1997) \\
\hline RMA1126 & RMA1030 pqaB: : MudJ & Baker et al. (1997) \\
\hline RMA1180 & Ty2 pqrA::MudJ & Baker et al. (1997) \\
\hline RMA2310 & Ty2 pqaA::MudJ & Baker et al. (1997) \\
\hline RMA2312 & Ty2 pqaD: : MudJ & Baker et al. (1997) \\
\hline RMA2316 & Ty 2 pqrB: : MudJ & Baker et al. (1997) \\
\hline RMA2326 & Ty 2 pqaB: : MudJ & Baker et al. (1997) \\
\hline RMA2526 & RMA1090 pqaB:: MudJ & Baker et al. (1997) \\
\hline RMA1307 & RMA2326 pmrA:: Tn10 & P22 on JSG421* \\
\hline RMA1309 & RMA2526 pmrA:: Tn10 & P22 on JSG421* \\
\hline
\end{tabular}

* Transduction with P22HTint105 propagated on S. typhimurium JSG421, selected for Tc ${ }^{\mathrm{r}}$.

for $1 \mathrm{~h}$. Cells were then washed three times with PBS and the $0 \mathrm{~h}$ timepoint taken by lysing cells with $0.5 \mathrm{ml} 0.1 \%(\mathrm{v} / \mathrm{v})$ Triton X-100 in PBS. All remaining wells were incubated in the appropriate assay media containing $10 \mu \mathrm{g}$ gentamicin $\mathrm{ml}^{-1}$ for the remainder of the assay. Subsequent timepoints were taken at 6,18 and $24 \mathrm{~h}$. All bacteria (including the initial inoculum) were diluted in saline and plated out for counts on LA plates. After $18 \mathrm{~h}$ incubation, the colonies were counted and the c.f.u. $\mathrm{ml}^{-1}$ at each timepoint was calculated.

Lactate dehydrogenase assay. Survival of the tissue culture cells during the bacterial-infection assays was determined using the CytoTox 96 Non-Radioactive Cytotoxicity Assay (Promega). We measured the amount of lactate dehydrogenase remaining in the cells as it may break down in the supernatant over $24 \mathrm{~h}$. Infected and control cells were washed three times with PBS, as for lysis for bacterial counts, but were then lysed with $200 \mu$ lysis buffer according to the manufacturer's instructions and assayed accordingly. A standard lactate dehydrogenase curve was performed with each assay to calculate the amount of lactate dehydrogenase units per well present at 0 and $24 \mathrm{~h}$ after bacterial infection.

Statistical analysis. Statistical analysis was performed using Student's two-tailed $t$-test for independent means.

DNA and Southern-blotting methods. The preparation of plasmid DNA, restriction enzyme digestion, ligation and agarose gel electrophoresis were performed as described previously (Morona et al., 1995). Southern blotting was performed as recently described (Morona et al., 1995). Hybridization and detection were performed with digoxigenin labelling and detection kits (Boehringer Mannheim), according to the manufacturer's instructions.
Cloning the S. typhi Ty2 pqaB gene. The $0.85 \mathrm{~kb}$ HindIII/ClaI fragment was isolated by a method based on the single specific primer (SSP)-PCR (Shyamala \& Ames, 1993). This method allows the amplification of a piece of DNA for which sequence is only available at one end. S. typhi pqaB::MudJ (RMA2326) chromosomal DNA was digested with HindIII/ClaI and ligated to similarly digested pBluescript $\mathrm{KS}+$; this ligation mix was then used as a template for a PCR reaction. The PCR was performed with oligonucleotides 2308 ( $5^{\prime}$ TCGCATTTATCGTGAAACGCTTTCG $3^{\prime}$; anneals to the MuR right end of MudJ before the HindIII site) and the M13 reverse primer for pBluescript KS + (Stratagene). The $0.85 \mathrm{~kb}$ PCR product was cloned into pGEMT (Progen) according to the manufacturer's instructions, to create pRMSB50. After transformation into E. coli $\mathrm{DH} 5 \alpha$, plasmid DNA was prepared and used for DNA sequencing on an Applied Biosystems 373A sequencer using the Applied Biosystems DNA Dye Terminator kit as recommended by the manufacturer. The $0.85 \mathrm{~kb}$ fragment was then labelled by digoxigenin-PCR and used to probe $S$. typhi Ty 2 chromosomal DNA digested with a number of restriction enzymes. The smallest fragment detected was an EcoRV fragment (approx. $3 \mathrm{~kb}$ ), and inverse PCR (Ochman $e t$ al., 1988) was used to obtain the fragment. This involved digesting $10 \mu \mathrm{g} S$. typhi Ty2 chromosomal DNA with EcoRV, circularization and religation of the restriction fragments, and amplification by PCR using oligonucleotides 2512 (5' CGATTCGCCATGAGCGATG $3^{\prime}$ ) and 2513 (5' CACGATCCAGTCGCCAGAC $3^{\prime}$ ) which anneal to nucleotides $735-753$ and 152-134, respectively, of the pqaB sequence. This PCR fragment was cloned into pGEMT to create pRMSB53, and transformed into $\mathrm{DH} 5 \alpha$ to enable sequencing. The EcoRV fragment was fully sequenced on both strands by Dye 
Terminator sequencing and was found to be $2.83 \mathrm{~kb}$ in size (GenBank AF0718082). Sequence analysis of S. typhi pqaB and adjacent genes, and the $S$. typhimurium pmrF operon (ORF17) (Gunn et al., 1998) was performed by using BLASTX/P (Altschul et al., 1990). Sequence alignments are available from the authors by request.

P22 bacteriophage propagation and transduction. P22HTint 105 (P22) bacteriophage propagation and transduction were performed according to the method described by Davis $e t$ al. (1980).

$\boldsymbol{\beta}$-Galactosidase assays. These were perfomed as described by Baker et al. (1997) on cultures grown in $\mathrm{LB}$ at $37^{\circ} \mathrm{C}$ with aeration for $16 \mathrm{~h}$.

PmB assays. Bacteria grown for $16 \mathrm{~h}$ in $\mathrm{LB}$ at $37^{\circ} \mathrm{C}$ with aeration were subcultured $(1: 20)$ in LB and grown to midexponential phase. These cultures were then diluted to approximately $1 \times 10^{4}$ bacteria $\mathrm{ml}^{-1}$ and chilled. Aliquots $(100 \mu \mathrm{l})$ of diluted culture were added to a 96 well microtitre plate (Corning wells catalogue no. 250850-96). One hundred microlitres of appropriately diluted $\mathrm{PmB}$ in PBS, $\mathrm{pH} 7 \cdot 5$, were added to each well. Controls consisted of bacteria $(100 \mu l)$ and PBS $(100 \mu \mathrm{l})$. The microtitre plates were incubated at $37^{\circ} \mathrm{C}$ for $1 \mathrm{~h}$, after which they were placed on ice. Plates (LA) were spread with $50 \mu$ from each well; the plates were incubated overnight at $37^{\circ} \mathrm{C}$ for $18 \mathrm{~h}$, and the colonies counted. The data are presented as percentage survival relative to the control with no added PmB.

LPS and SDSPAGE silver staining. The S. typhimurium C5, $\mathrm{PhoP}^{-}$and $\mathrm{PhoP}^{\mathrm{c}}$ strains and all the S. typhi strains (Ty2, $\mathrm{PhoP}^{-}, \mathrm{PhoP}^{\mathrm{c}}$ and $p q a / p q r:: \mathrm{MudJ}$ fusion strains) were serotyped by the Salmonella Reference Laboratory (The Institute of Medical and Veterinary Science, Adelaide) and found to be identical to the wild-type strains. All Salmonella strains were grown for $16-18 \mathrm{~h}$ at $37^{\circ} \mathrm{C}$ in $\mathrm{LB}$ with aeration. Small-scale LPS preparations were made by proteinase $\mathrm{K}$ treatment of whole-cell lysates (Hitchcock \& Brown, 1983). After electrophoresis on SDS-20\% polyacrylamide gels, LPS was detected by silver staining as described previously (Morona et al., 1991).

\section{RESULTS}

\section{Invasion and net growth of S. typhi strains in PMA- differentiated $\mathbf{0} 937$ cells}

As S. typhimurium $\mathrm{PhoP}^{-}$and $\mathrm{PhoP}^{\mathrm{c}}$ mutants have previously been shown to have decreased survival in macrophage cell lines, because of the host specificity of these typhoid-fever causing Salmonella species, we wished to assess $S$. typhi Ty2 and phoP/Q-mutant derivatives in a human macrophage cell line for their ability to invade and grow. S. typhi strain Ty2 and the isogenic PhoP- (RMA1030) and $\mathrm{PhoP}^{\mathrm{c}}$ (RMA1090) strains were assessed for their ability to invade and grow in the macrophage-like PMA-U937 cells (Tables 2 and 3 ; Fig. 1a). The S. typhi PhoP $^{-}$mutant invaded as well as the wild-type Ty2 strain; however, an approximate 10fold decrease in invasion for $\mathrm{PhoP}^{\mathrm{c}}$ was noted (Fig. 1a, Table 2). This correlated with data from an S. typhimurium $\mathrm{PhoP}^{\mathrm{c}}$ mutant which had previously been shown to have reduced invasion (Behlau \& Miller, 1993). The net growth index (GI) at $24 \mathrm{~h}$ for Ty2 in the differentiated U937 cells was $15-25$, and the $\mathrm{PhoP}^{\mathrm{c}}$ strain
Table 2. Invasion of PMA-U937 cells by S. typhi and S. typhimurium strains

Invasion percentages were calculated by dividing the number of bacteria at time 0 after gentamicin treatment by the number of bacteria initially added, multiplied by 100 . Results were calculated from data in Figs 1 and 2 and are presented as the mean $\pm \mathrm{sD}$.

\begin{tabular}{|lc|}
\hline Strain & Percentage invasion \\
\hline S. typhi & \\
Ty2 $\left(\mathrm{PhoP}^{+}\right)$ & $6 \cdot 3 \pm 2 \cdot 5$ \\
RMA1030 $\left(\mathrm{PhoP}^{-}\right)$ & $3 \cdot 3 \pm 1 \cdot 3$ \\
RMA1090 $\left(\mathrm{PhoP}^{\mathrm{c}}\right)$ & $0 \cdot 9 \pm 0 \cdot 69$ \\
RMA2326 (pqaB::MudJ) & $4 \cdot 9 \pm 2 \cdot 5$ \\
S. $\boldsymbol{t}$ yphimurium & \\
C5 (PhoP $\left.{ }^{+}\right)$ & $95 \cdot 7 \pm 4 \cdot 7$ \\
RMA1010 $\left(\mathrm{PhoP}^{-}\right)$ & $82 \cdot 7 \pm 4 \cdot 8$ \\
RMA1024 $\left(\mathrm{PhoP}^{\mathrm{c}}\right)$ & $14 \cdot 5 \pm 2 \cdot 6$ \\
\hline
\end{tabular}

Table 3. Growth index of S. typhi and S. typhimurium in PMA-U937 cells

ND, Not done.

\begin{tabular}{|c|c|c|}
\hline \multirow[t]{2}{*}{ Bacterial strain } & \multicolumn{2}{|c|}{ Growth index } \\
\hline & HeLa & PMA-U937 \\
\hline \multicolumn{3}{|l|}{ S. typhi } \\
\hline Ty2 $\left(\mathrm{PhoP}^{+}\right)$ & $6^{*}$ & $15-25 \dagger$ \\
\hline RMA1030 (PhoP $\left.{ }^{-}\right)$ & $6^{*}$ & $2-3 \dagger$ \\
\hline RMA1090 (PhoPc) & $6^{*}$ & $42^{*}$ \\
\hline RMA2326 (pqaB::MudJ) & $5^{*}$ & $3^{*}$ \\
\hline \multicolumn{3}{|l|}{ S. typhimurium $\ddagger$} \\
\hline C5 $\left(\mathrm{PhoP}^{+}\right)$ & ND & 7 \\
\hline RMA1010 (PhoP-) & ND & 32 \\
\hline RMA1024 $\left(\right.$ PhoP $\left.^{\mathrm{c}}\right)$ & ND & 10 \\
\hline
\end{tabular}

* Growth index for these strains was calculated by the number of bacteria at $24 \mathrm{~h}$ divided by the number of bacteria at $0 \mathrm{~h}$.

fGrowth index for these strains was calculated from data in Fig. 1.

$\neq$ Growth index for $S$. typhimurium strains was calculated by the number of bacteria at $18 \mathrm{~h}$ divided by the number of bacteria at $0 \mathrm{~h}$ and was calculated from data in Fig. 2.

(RMA1090) had a GI of 42 (Fig. 1; Table 3); a possible explanation for this increased net growth of the $S$. typhi $\mathrm{PhoP}^{\mathrm{c}}$ strain compared to $\mathrm{Ty} 2$ is discussed later. The $\mathrm{PhoP}^{-}$strain (RMA1030) was limited in intracellular net growth (GI 2-3) when compared to the wild-type strain. As the difference in net growth between Ty2 and RMA1030 was significant $(P<0.02$ at $24 \mathrm{~h}$, Student's $t$ test), we assayed previously identified S. typhi $p q a / p q r$ mutants (Baker et al., 1997) for invasion and intracellular net growth in PMA-U937 cells. All five S. typhi pqa/pqr::MudJ mutant strains (pqaA::MudJ, pqaB 


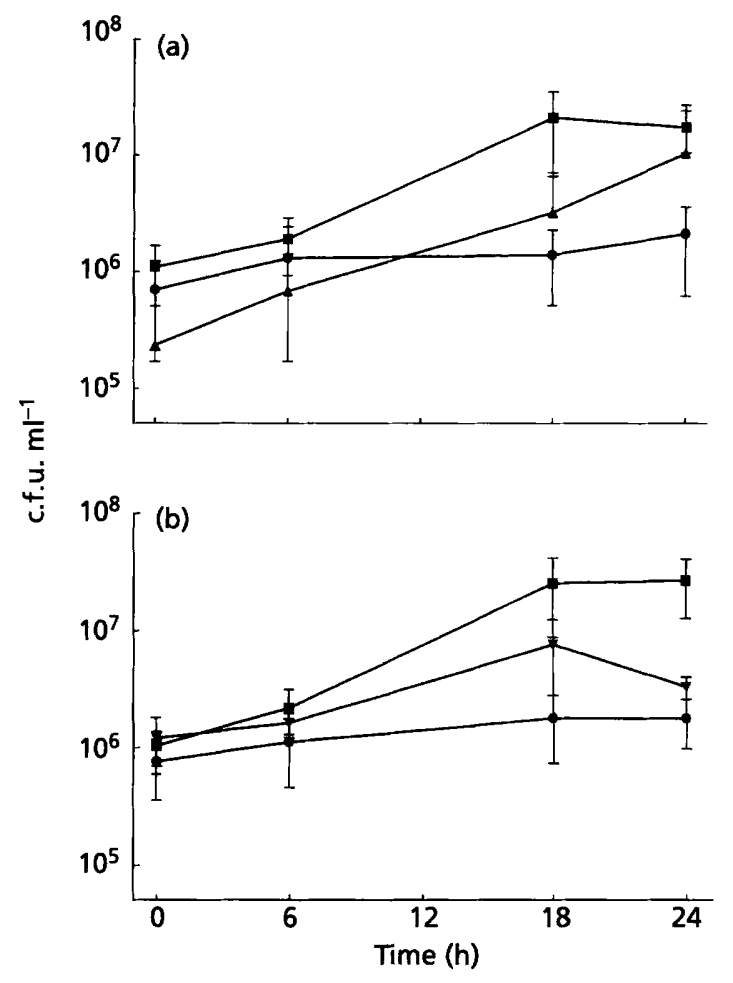

Fig. 1. Net growth of S. typhi strains in PMA-U937 cells. (a) Net

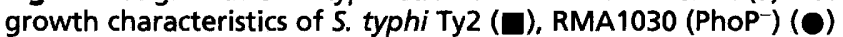
and RMA1090 (PhoP) (A) strains after invasion of PMAdifferentiated U937 cells. (b) Net growth characteristics of $S$. typhi Ty2 (足, RMA1030 (PhoP ${ }^{-}$) (O) and RMA2326 (pqaB::MudJ) ( $\nabla$ ) strains after invasion of PMA-differentiated U937 cells. S. typhi strains were added at a ratio of 10:1 (bacteria:cells). Each point represents the arithmetic mean of four assays expressed as c.f.u. $\mathrm{ml}^{-1} \pm$ SD. Data for (a) and (b) are from separate experiments.

$:: \mathrm{MudJ}$, pqaD : :MudJ, pqrA ::MudJ and pqrB ::MudJ) tested were unaffected in their ability to invade PMAU937 cells. Only the pqaB::MudJ mutant (RMA2326) showed a decrease in intracellular net growth (GI 3) compared to the wild-type strain $(P<0.02$ at $24 \mathrm{~h}$ ) (Fig. 1b, Table 3).

\section{Growth of $S$. typhi strains in HeLa cells}

To demonstrate that the intracellular growth deficiencies of the S. typhi PhoP $\mathrm{P}^{-}$and pqaB::MudJ mutants were specifically related to the nature of the macrophage-like PMA-U937 cells, we tested these strains in an epithelial (non-macrophage) cell line. The S. typhi Ty 2 wild-type, isogenic PhoP ${ }^{-}$(RMA1030), PhoP $^{\mathrm{c}}$ (RMA1090) and pqaB::MudJ (RMA2326) strains were assessed for their ability to grow inside HeLa cells (Table 3 ). All four strains grew to give a GI of 5-6, which correlated with data previously reported for $S$. typhi intracellulargrowth levels in HeLa cells (Mills \& Finlay, 1994), and indicated that the $\mathrm{PhoP}^{-}$and $p q a B$ mutations selectively affected $S$. typhi intra-macrophage net growth inside PMA-U937 cells. S. typhi Ty2, PhoP ${ }^{-}$(RMA1030) and pqaB::MudJ (RMA2326) strains gave similar levels of

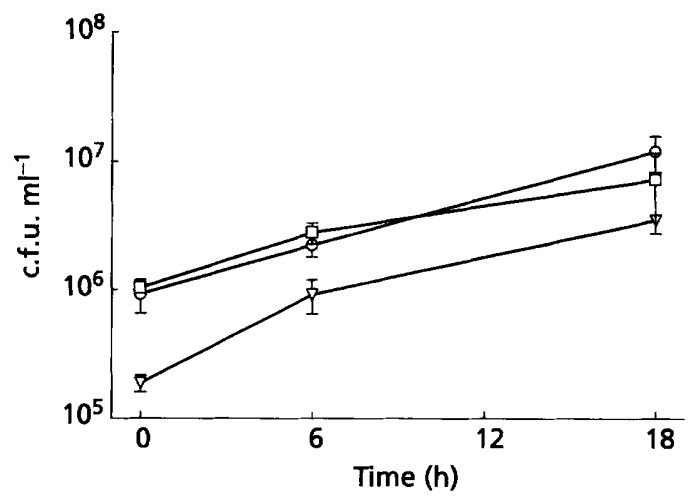

Fig. 2. Net growth of S. typhimurium strains in PMA-U937 cells. This figure shows the net growth characteristics of $S$. typhimurium C5 ( $\square$ ), RMA1010 (PhoP') (O) and RMA1024 (PhoPC) $(\nabla)$ strains after invasion of PMA-differentiated U937 cells. S. typhimurium strains were added at a ratio of $1: 1$ (bacteria:cells). Each point represents the arithmetic mean of three assays expressed as c.f.u. $\mathrm{ml}^{-1} \pm$ SD.

invasion, with a 10 -fold invasion defect for the $\mathrm{PhoP}^{\mathrm{c}}$ strain (RMA1090) (data not shown). The GI results for the S. typhi $\mathrm{PhoP}^{-}$and $\mathrm{PhoP}^{\mathrm{c}}$ strains agree with data reported for S. typhimurium $\mathrm{PhoP}^{-}$and $\mathrm{PhoP}^{\mathrm{c}}$ strains; the latter showed no intracellular-growth deficiency compared to wild-type in an epithelial cell line (Miller \& Mekalanos, 1990).

\section{Invasion and net growth of S. typhimurium strains in PMA-U937 cells}

As the S. typhi $\mathrm{PhoP}^{-}$mutant was defective in net growth in the PMA-U937 cell line compared to the wildtype Ty2 strain, we wanted to know whether the $S$. typhimurium $\mathrm{PhoP}^{-}$mutant would show a similar defect in net growth compared to the parent C5 strain. Therefore we investigated the ability of $S$. typhimurium C5 and isogenic $\mathrm{PhoP}^{-}$(RMA1010) and $\mathrm{PhoP}^{\mathrm{C}}$ (RMA1024) mutants, to invade and grow within PMAU937 cells. We found that after $24 \mathrm{~h}$ in the PMA-U937 cells, the S. typhimurium cells caused the macrophagelike cells to die and lyse, as indicated by lack of trypan blue exclusion (data not shown). Therefore, the $S$. typhimurium PMA-U937 assay was only taken to $18 \mathrm{~h}$ rather than the $24 \mathrm{~h}$ used for S. typhi. We observed that the $S$. typhimurium strains had a greatly increased level of invasion (approx. 10- to 20-fold) compared to S. typhi strains (Table 2); this has been noted before for HeLa cell invasion (Mills \& Finlay, 1994). Therefore the m.o.i. for S. typhimurium was adjusted to $1: 1$ instead of $10: 1$ used for S. typhi so the numbers of bacteria invading the PMA-differentiated U937 cells were similar for both species. The S. typhimurium $\mathrm{PhoP}^{\mathrm{c}}$ mutant (RMA1024) showed the expected invasion defect compared to the wild-type and $\mathrm{PhoP}^{-}$derivative (Table 2) (Behlau \& Miller, 1993). The S. typhimurium PhoP $^{-}$mutant had no net growth limitations compared to the $S$. typhimurium wild-type strain (Fig. 2), and actually gave a higher GI 
Table 4. Lactate dehydrogenase (LDH) assay for S. typhi infection of PMA-U937 cells

\begin{tabular}{|c|c|c|c|c|}
\hline Bacterial strain & $\begin{array}{l}\text { Units LDH per } \\
\text { well }(0 \mathrm{~h})^{*}\end{array}$ & $\begin{array}{l}\text { Fold decrease } \\
\qquad(\mathbf{0} \text { h }) \dagger\end{array}$ & $\begin{array}{l}\text { Units LDH per } \\
\text { well }(24 h)^{*}\end{array}$ & $\begin{array}{l}\text { Fold decrease } \\
\qquad(24 \mathrm{~h}) \dagger\end{array}$ \\
\hline None & $4.03 \times 10^{-3} \pm 1.47 \times 10^{-3}$ & $1 \cdot 00$ & $3.50 \times 10^{-3} \pm 9.22 \times 10^{-4}$ & 0.87 \\
\hline Ty2 $\left(\mathrm{PhoP}^{+}\right)$ & $2.03 \times 10^{-3} \pm 9 \cdot 25 \times 10^{-4}$ & $0 \cdot 50$ & $1.09 \times 10^{-3} \pm 9.47 \times 10^{-4}$ & $0 \cdot 27$ \\
\hline RMA1030 (PhoP $\left.{ }^{-}\right)$ & $1.96 \times 10^{-3} \pm 1.15 \times 10^{-3}$ & 0.49 & $1.16 \times 10^{-3} \pm 9 \cdot 55 \times 10^{-4}$ & 0.29 \\
\hline RMA1090 $\left(\mathrm{PhoP}^{\mathrm{c}}\right)$ & $2.98 \times 10^{-3} \pm 1.55 \times 10^{-3}$ & 0.74 & $2.41 \times 10^{-3} \pm 1.25 \times 10^{-3}$ & 0.60 \\
\hline RMA2326 (pqaB::MudJ) & $2.92 \times 10^{-3} \pm 1.27 \times 10^{-3}$ & 0.72 & $2.30 \times 10^{-3} \pm 1.50 \times 10^{-3}$ & 0.57 \\
\hline
\end{tabular}

*Units LDH per well are presented as the mean of four assays \pm SD.

†Fold decrease is the decrease in units LDH per well compared to uninfected cells at time 0.

than wild-type (Table 3). Hence the net growth restriction for S. typhi in PMA-U937 cells caused by the $\mathrm{PhoP}^{-}$mutation appeared to be specific for S. typhi.

\section{Lactate dehydrogenase assay}

The PMA-U937 assay appeared to differentiate between S. typhi Ty $2, \mathrm{PhoP}^{-}$and $p q a B:: \mathrm{MudJ}$ mutant strains by the bacterial GI. However, we needed to know whether the differences in the Salmonella c.f.u. $\mathrm{ml}^{-1}$ at the timepoints (particularly 0 and $24 \mathrm{~h}$ ) for the PMA-U937 cell assay were actually due to net growth differences between Salmonella strains and not because the bacteria had a cytotoxic effect on the infected macrophage-like cells, therefore resulting in a lower c.f.u. $\mathrm{ml}^{-1}$ count. By visual inspection, the majority of the infected cells still adhered to the bottom of the 24 well trays at $24 \mathrm{~h}$ and most of these excluded trypan blue, indicating that they were viable. As a further test, we assayed lactate dehydrogenase, which is a stable cytosolic enzyme released during cells lysis, and can therefore be used to evaluate the amount of PMA-U937 cells remaining viable over the $24 \mathrm{~h}$ assay. We tested the amount of lactate dehydrogenase contained within the PMA-U937 cells during infection of various Salmonella strains (Table 4). The data shows a $25-35 \%$ variation in the number of PMA-U937 cells per well before bacterial infection (Table 4) which is consistent with data for other adherent cells lines (Monack et al., 1996). This difference in the number of PMA-U937 cells may explain the large error bars seen in Figs 1 and 2. Both S. typhi Ty2 and $\mathrm{PhoP}^{-}$(RMA1030) strains caused some cytolysis of the U937 cells during invasion but at $24 \mathrm{~h}$, the damage was approximately the same, indicating that the difference in GI (Table 3) between the two strains is not due to differences in PMA-U937 cytolysis by the bacteria. Both the S. typhi PhoP (RMA1090) and pqaB:: MudJ (RMA2326) strains also caused some cytolysis of PMA-U937 cells, although less than wildtype. PMA-U937 cells infected with S. typhimurium strains were also tested for release of lactate dehydrogenase and at $18 \mathrm{~h}$ the bacteria gave a similar level of cytolysis of the PMA-U937 cells to the S. typhi Ty2 strain at $24 \mathrm{~h}$ (data not shown).

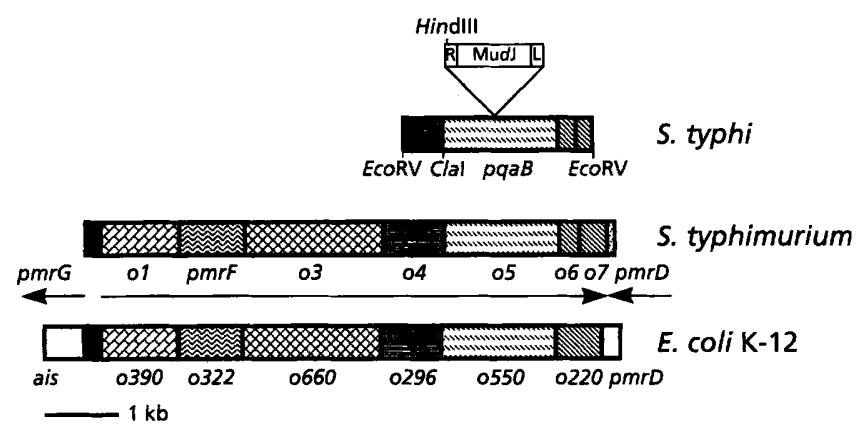

Fig. 3. The location of the sequenced EcoRV fragment (AF0718082) containing the $S$. typhi pqaB gene and surrounding genes. The $S$. typhimurium pmrF operon (AF036677) and homologous E. coli (AE000315) region are also shown. The site of the MudJ insertion between nucleotides 847 and 848 of the $S$. typhi pqaB gene is shown. Relevant restriction sites are also indicated. Arrows indicate direction of transeription.

\section{Cloning and sequencing of the S. typhi pqaB gene}

Our experiments suggested that the $S$. typhi pqaB gene was required for wild-type level of net growth/survival in PMA-U937 cells. Therefore we isolated and sequenced this gene from S. typhi. Southern analysis of the pqaB::MudJ insertion mutant chromosome with a probe to the right hand side of MudJ (MuR), which would contain part of the transposon and chromosomal DNA corresponding to $p q a B$, enabled us to identify a pqaB:: MudJ 0.85 kb HindIII/ClaI end fragment (data not shown). The $0.85 \mathrm{~kb}$ fragment was isolated, cloned into pGEMT to create pRMSB50 and sequenced (Methods). The fragment was found to have $70 \%$ homology with an E. coli K-12 ORF (AE000315, ORF o550) and $\sim 98 \%$ homology with the fifth gene of an $S$. typhimurium PmrA/B-regulated $p m r F$ operon (AF036677; Gunn et al., 1998). A larger 2.83 kb EcoRV fragment was then isolated (Methods), sequenced (AF0718082) and found to contain the whole pqaB gene plus adjacent sequence with strong homology to the $S$. typhimurium pmrF operon ORF4, ORF6 and ORF7 (Fig. 3) (Gunn et al., 1998). The MudJ insertion was 


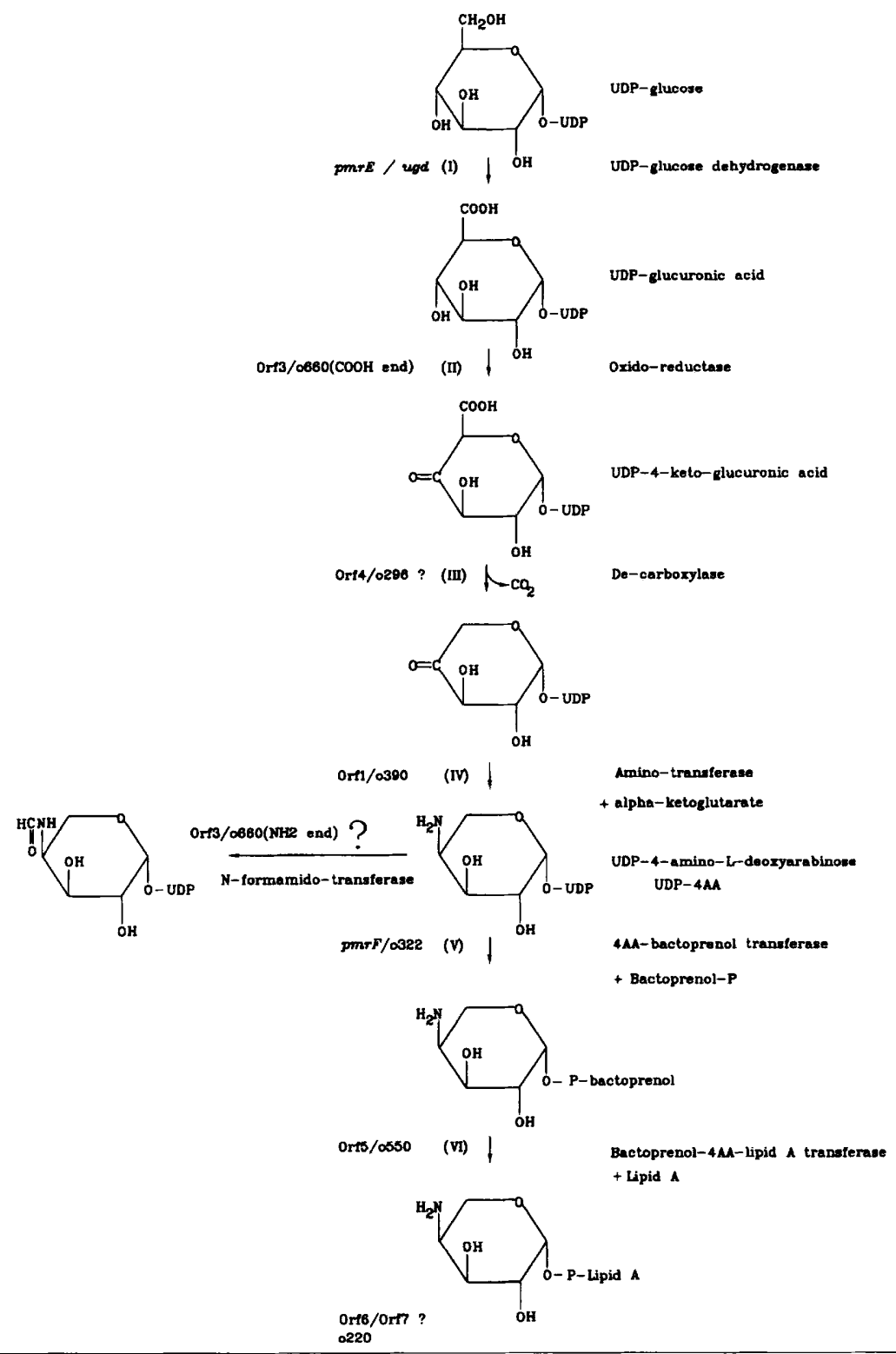

Fig. 4. Putative pathway for the biosynthesis of L-deoxy-4AA and modification of lipid A. The predicted functions of individual $p m r F$ operon gene products are described in the text.

found to be between nucleotides 847 and 848 of the $p q a B$ gene (Fig. 3).

\section{Putative biosynthesis pathway for 4AA}

The S. typhimurium $p m r F$ operon was recently identified as being both $\mathrm{PhoP} / \mathrm{Q}$ and $\mathrm{Pmr} / \mathrm{B}$ regulated and highly likely to encode the enzymes required for the biosynthesis of the 4-aminoarabinose (4AA) modification of the lipid A component of LPS (Gunn et al., 1998). The $p m r F$ mutation was shown to be in the second ORF of the operon and we have shown that pqaB::MudJ is a mutation in ORF5 of this operon. To obtain an understanding of the possible role of the $p m r F$ and ORF5/pqaB gene products in 4AA-lipid A modification, we analysed the ORFs in the operon by BLASTX/BLASTP computer homology analysis to obtain a speculative pathway for biosynthesis of 4AA and the modification of lipid A by 4AA.
The de novo biosynthesis of $\mathrm{C}_{5}$ monosaccharides has been extensively studied in plants (Feingold \& Barber, 1990; Tenhaken \& Thulke, 1996). UDP-glucuronic acid is the key precursor, and is obtained from the metabolic pool by the action of UDP-glucose dehydrogenase on UDP-glucose (Fig. 4, step I). UDP-glucose dehydrogenase is predicted to be encoded by the remotely located pmrE (ugd) gene (Gunn et al., 1998; Groisman et al., 1997; Morona et al., 1995; Valdivia \& Falkow, 1996). The enzymes encoded by the $p m r F / p q a B$ operon are then predicted to act on UDP-glucuronic acid. Initially, an oxido-reductase encoded by ORF 3 converts UDP-glucuronic acid to UDP-4-keto-glucuronic acid (Fig. 4, step II). This activity is encoded by the carboxyterminal half of ORF 3 , which has approximately $26 \%$ identity with a variety of dehydratases, and in common with this class of enzymes has an NAD-binding motif (GXXGXXG) near the start of the dehydratase domain of the 660 aa protein. The next step is the removal of the 
carboxyl group in a decarboxylation reaction (Fig. 4, step III). The nature of the enzymes which perform this step are poorly characterized and no sequences have been reported. The only ORF which could potentially be assigned as encoding this function is ORF4, which encodes a hydrophilic protein. The decarboxylation reaction results in a $C_{5}$ keto intermediate, which could be stereo-specifically reduced at the C-4 position by an amino-transferase encoded by ORF1 (Fig. 4, step IV) and results in UDP-4AA. The ORF1 protein shows approximately $34 \%$ identity with other proteins predicted to perform this reaction, thereby resulting in a variety of 4-amino monosaccharides, e.g. perosamine (Stroeher et al., 1995). The following two steps result in lipid A modification by 4AA. The PmrF protein has both amino acid sequence and hydropathy profile similarity with the Bgt protein of Shigella flexneri (Mavris et al., 1997). In reactions analogous to those recently described for glucosylation of the $S$. flexneri $\mathrm{O}$-antigen (Mavris et al., 1997), 4AA is transferred to bactoprenol to form 4AA-P-bactoprenol by the $p m r F$-encoded glycosyl transferase (Fig. 4, step V), and from this intermediate, 4AA is transferred to a free phosphate on lipid A by a specific transferase encoded by ORF5 (Fig. 4, step VI). The 550 aa ORF5 protein is highly hydrophobic with multiple potential membrane-spanning regions, and little similarity to other proteins. In this regard, it is similar to the specific glucosyl transferases (GtrX, GtrI, GtrII, $\mathrm{GtrV}$ ) which modify the $S$. flexneri $\mathrm{O}$-antigen (Verma et al., 1993; Bastin et al., 1997; Huan et al., 1997a, b; Mavris et al., 1997). The remaining unassigned ORFs 6 and 7 (ORF6 in the E. coli K-12 operon) encode small, highly hydrophobic proteins with no discernible similarity with other proteins or ORFs. An interesting aside is that the amino-terminal half of the ORF3 protein has approximately $28 \%$ identity with proteins able to formylate a variety of molecules. We speculate that the amino group of $4 \mathrm{AA}$ can be formylated by this domain of ORF3 (Fig. 4, step VII). This type of modification has been reported for the 4-amino sugar component (perosamine) of the O-antigen of Brucella sp. (Moreno et al., 1987). The presence of this modification on 4-AA has not been reported.

\section{PmrA/B regulation of the S. typhi pqaB gene}

The $S$. typhimurium pmrF operon has been shown to be strongly regulated by PmrA/B (Gunn et al., 1998). To test whether the $S$. typhi pqaB gene was also regulated by $\mathrm{PmrA} / \mathrm{B}$, a $p m r A$ null mutation ( $p m r A:: \operatorname{Tn} 10 \mathrm{~d}$ ) from the $S$. typhimurium strain JSG421 was transduced by phage P22 into S. typhi pqaB::MudJ, $\mathrm{PhoP}^{+}$ (RMA2326), and pqaB::MudJ, PhoP ${ }^{\mathrm{c}}$ (RMA2356) strains, to create RMA1307 and RMA1309, respectively. These strains produced white colonies on LA + X-Gal plates compared to the intense blue colonies of their $p m r A^{+}$parent strains. This indicated that the S. typhi pqaB::MudJ fusion was strongly regulated by the PmrA/B operon. $\beta$-Galactosidase assays were performed on overnight cultures grown in LB, as described in Methods. The results are given for each S. typhi strain,

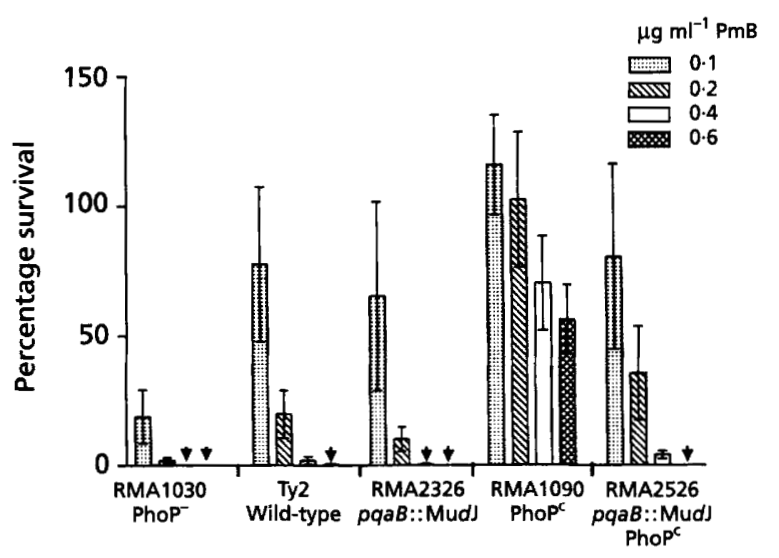

Fig. 5. PmB resistance of $S$. typhi strains. This figure shows the percentage survival of S. typhi RMA1030 (PhoP-), Ty2, RMA2326 (pqaB::MudJ), RMA1090 (PhoP) and RMA2526 (pqaB::MudJ, PhoP) strains after exposure for $1 \mathrm{~h}$ to four concentrations $(0.1$, $0.2,0.4$ and $0.6 \mu \mathrm{g} \mathrm{ml}^{-1}$ ) of PmB at $37^{\circ} \mathrm{C}$. Each bar represents the arithmetic mean of three assays, expressed as percentage survival \pm SD. Arrows indicate survival $\leqslant 1 \%$.

and presented as $\beta$-galactosidase units from the mean of two duplicate assays \pm SD: RMA1126 (PhoP $^{-}$,

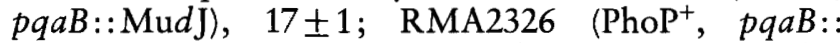
MudJ), $395 \pm 1$; RMA2526 (PhoP', pqaB::MudJ), 996 $\pm 35 ;$ RMA1307 $\left(\mathrm{PhoP}^{+}\right.$, pqaB::MudJ $p m r A::$

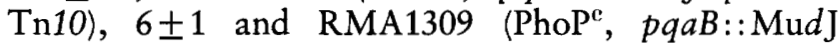
$p m r A:: \operatorname{Tn} 10), 8 \pm 4$. These results showed that $p q a B$ expression was PmrA/B dependant, as the $\beta$-galactosidase activity of $S$. typhi RMA1307 and RMA1309 strains were greatly down-regulated (66- and 125-fold, respectively) compared to their $p m r A^{+}$parental strains.

\section{PmB sensitivity of S. typhi pqaB mutant}

Since the $S$. typhimurium $p m r F$ mutant is sensitive to $\mathrm{PmB}$, compared to the wild-type strain (Gunn et al., 1998), we tested the sensitivity of the S. typhi pqaB mutant to this antimicrobial agent. Previous assays with other antimicrobial agents such as melittin and protamine (Baker et al., 1997) indicated that S. typhi was approximately 10 -fold more sensitive to these agents than $S$. typhimurium. In preliminary experiments, we found that $S$. typhi Ty 2 was approximately 10 -fold more sensitive to PmB than the S. typhimurium C5 strains. The survival of $S$. typhi Ty2, RMA1030 (PhoP ${ }^{-}$), RMA1090 (PhoP ${ }^{\mathrm{e}}$,, RMA2326 (pqaB::MudJ), RMA2526 (pqaB::MudJ, PhoP ${ }^{\mathrm{c}}$, RMA1307 (pqaB, pmrA::Tn10) and RMA1309 (pqaB, pmrA::Tn10, $\left.\mathrm{PhoP}^{\mathrm{c}}\right)$ strains were tested with four concentrations of $\operatorname{PmB}\left(0.1,0.2,0.4\right.$ and $\left.0.6 \mu \mathrm{g} \mathrm{m}^{-1}\right)$ and the results are shown in Fig. 5. The difference between percentage survival of S. typhi Ty2 and RMA1030 ( $\mathrm{PhoP}^{-}$) was small, however RMA1090 (PhoP ${ }^{\mathbf{c}}$ ) showed increased resistance to $\mathrm{PmB}$ (discussed below); this correlates with previous S. typhimurium data (Gunn et al., 1998; Groisman et al., 1997). Little or no difference was seen 


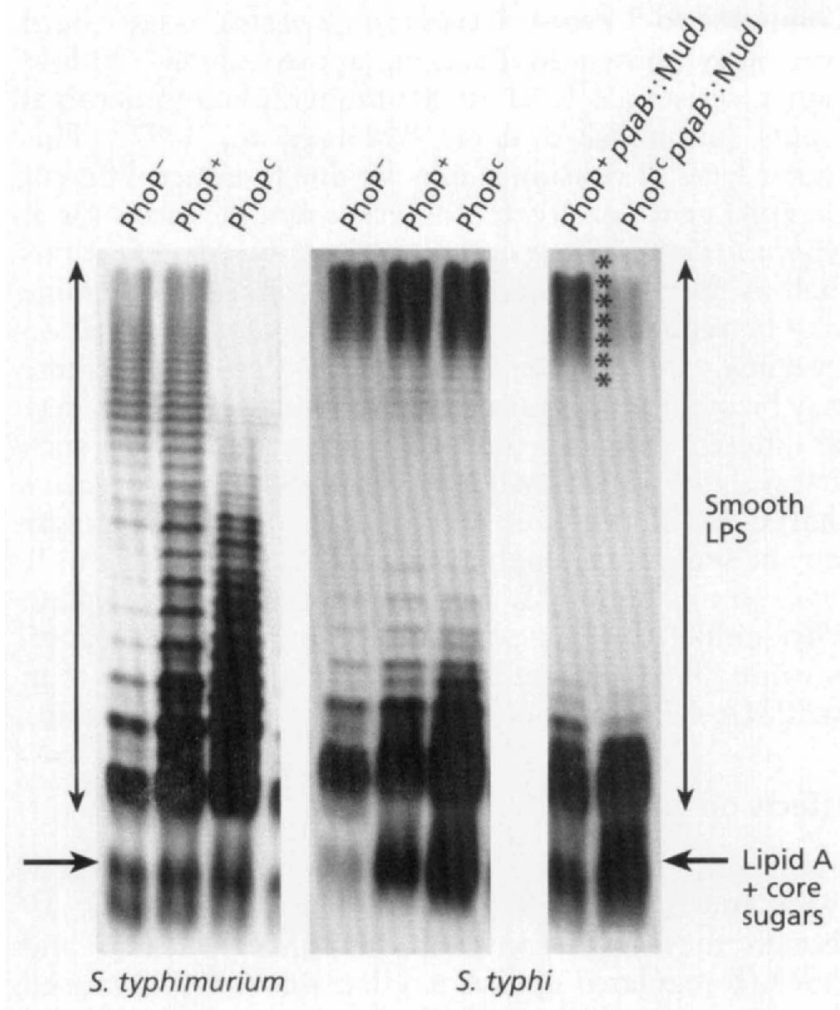

Fig. 6. Comparison of $S$. typhi and $S$. typhimurium lipopolysaccharides. Samples (representing $10^{8}$ cells) were prepared from $18 \mathrm{~h}$ cultures and electrophoresed on an SDS$20 \%$ polyacrylamide gel, then subjected to silver staining to detect LPS. The strains in each lane are: $S$. typhimurium RMA1010 (PhoP-), S. typhimurium C5 $\left(\mathrm{PhoP}^{+}\right)$, S. typhimurium RMA1024 (PhoP'), S. typhi RMA1030 (PhoP), S. typhi Ty2 $\left(\mathrm{PhoP}^{+}\right.$), S. typhi RMA1090 (PhoP), S. typhi RMA2326 (pqaB::MudJ, PhoP ${ }^{+}$) and S. typhi RMA2526 (pqaB::MudJ, PhoPC). ${ }^{* * *}$ indicates that the LPS chains lack discrete banding. Smooth LPS O-antigen chains and lipid A + core sugar molecules are also indicated.

between $S$. typhi Ty2 and the pqaB::MudJ insertion mutant (RMA2326), but a large difference was observed between the RMA2526 (pqaB::MudJ, PhoP ) and RMA1090 (PhoP') strains. These data indicate that the modifications to the LPS by this operon affect $\mathrm{PmB}$ resistance in both S. typhi and S. typhimurium.

\section{Comparison between S. typhi and S. typhimurium LPS}

Since the S. typhimurium pmrF operon affects lipid A modifications and both $p q a B$ in $S$. typhi and $p m r F$ in $S$. typhimurium affect $\mathrm{PmB}$ resistance, we decided to examine the LPS produced by $S$. typhi and $S$. typhimurium wild-type, $\mathrm{PhoP}^{-}$and $\mathrm{PhoP}^{\mathrm{c}}$ strains, and $S$. typhi strains with the $p q a B$ mutation in $\mathrm{PhoP}^{+}$and PhoP $^{\mathrm{c}}$ backgrounds. As shown in Fig. 6, the LPS profile of S. typhi Ty2 and S. typhimurium C5 wild-type strains showed minor differences compared to that of their respective isogenic PhoP ${ }^{-}$mutants. However the LPS of the S. typhimurium PhoPc (RMA1024) strain had a dramatically shorter $\mathrm{O}$-antigen chain compared to the wild-type and $\mathrm{PhoP}^{-}$strains (Fig. 6). There was little difference between the LPSs of the S. typhi PhoP (RMA1090), wild-type (Ty2) and $\mathrm{PhoP}^{-}$(RMA1030) strains. A subtle difference between the LPS of the $S$. typhi pqaB mutants (RMA2326 and RMA2356) and their wild-type (Ty2) and PhoP ${ }^{\mathrm{c}}$ (RMA1090) counterparts could be seen as the lack of discrete LPS bands in the high molecular mass range (marked by **** in Fig. 6). The lack of discrete bands was more apparent with RMA2526 (pqaB:: MudJ, PhoP ${ }^{c}$ ), which also seemed to have LPS with a reduced number of $\mathrm{O}$-antigen chains; this result was reproduced on three separate occasions (data not shown). Fig. 6 also shows that the LPS of $S$. typhi Ty2 has $\mathrm{O}$-antigen chains with a larger modal chain length than the LPS of S. typhimurium C5.

\section{DISCUSSION}

\section{Salmonella and the PMA-U937 tissue-culture model}

In this study, we used a tissue-culture model (PMAdifferentiated U937 cells) to study the invasion and intracellular net growth of $S$. typhi wild-type, $\mathrm{PhoP}^{-}$, $\mathrm{PhoP}^{\mathrm{c}}$ and $p q a / p q r$ mutants in macrophage-like cells. The invasion and net growth of S. typhimurium wildtype, $\mathrm{PhoP}^{-}$and $\mathrm{PhoP}^{\mathrm{c}}$ derivatives in PMA-U937 cells was also investigated. The $S$. typhi strains mentioned above were also assayed in an epithelial (HeLa) cell line to test for general defects in intracellular net growth.

The PMA-U937 cell assay was able to differentiate between S. typhi Ty2 and its $\mathrm{PhoP}^{-}$derivative (Fig. $1 \mathrm{~b}$, Table 3), indicating that it was a suitable assay to test the S. typhi pqa/pqr mutants. The S. typhi $\mathrm{PhoP}^{-}$and $\mathrm{PhoP}^{\mathrm{c}}$ mutants did not show a net growth defect compared to wild-type S. typhi Ty2, in the HeLa cell assay (Table 1), indicating that any net growth defects in the PMA-U937 cell assay were specific to the macrophage-like cells. The assay also appeared to be specific for $S$. typhi strains, as there was no intracellular net growth defect for the S. typhimurium $\mathrm{PhoP}^{-}$(RMA1010) strain, which was comparable to that of wild-type $S$. typhimurium C5 (Fig. 2, Table 3). Possible reasons for this will be discussed below. The data for the $S$. typhi $\mathrm{PhoP}^{\mathrm{c}}$ mutant do not correlate with published observations with an $S$. typhimurium $\mathrm{PhoP}^{\mathrm{c}}$ mutant, which was defective in intracellular net growth within macrophages (Miller \& Mekalanos, 1990). The observed difference may be due to the use of a human macrophage-like cell line for our experiments, as opposed to the mouse macrophage cell line used by Miller $\&$ Mekalanos (1990). We also observed no net growth restriction for the $S$. typhimurium $\mathrm{PhoP}^{\mathrm{c}}$ (RMA1024) mutant in the PMA-U937 cells, where growth was comparable to that of S. typhimurium C5 (Fig. 2, Table $3)$.

The S. typhipqaB (RMA2326) mutant had a significantly lower intracellular net-growth level at $24 \mathrm{~h}$ compared to S. typhi Ty2 in PMA-U937 cells $(P<0.02)$, however its net growth was not affected compared to the wild-type strain in HeLa cells (Table 3), indicating that the 
intracellular net growth defect was specific to the macrophage-like PMA-U937 cell line. Strain RMA2326 was found to be defective in net growth in PMA-U937 cells during the last $6 \mathrm{~h}$ of infection but overall was not as deficient in intracellular net growth as the $S$. typhi PhoP $^{-}$mutant (RMA1030) (Fig. 1b). This indicates that other $p q a$ genes are involved with $S$. typhi intramacrophage survival.

\section{S. typhi pqaB gene}

The S. typhi pqaB gene was cloned and sequenced along with adjacent genes, and was found to have a high $(\sim 98 \%)$ level of homology to ORF5 of the S. typhimurium pmrF operon (Fig. 3). The S. typhimurium $p m r F$ operon has been identified as being involved with 4AA-lipid A modification and PmB resistance (Gunn et al., 1998). A putative pathway for the biosynthesis of 4AA based on sequence alignments and predicted biochemistry is described in Fig. 4 and strongly suggests that pqaB/ORF5 encodes a bactoprenol-4AA-lipid A transferase. The $p m r F$ operon was found to be strongly regulated by the PmrA/B operon. A $p m r A:: \operatorname{Tn} 10 \mathrm{~d}$ mutation was transduced into our $p q a B:: M u d J$ mutant and expression of the S. typhi pqaB::MudJ fusion was strongly reduced. Hence $p q a B / O R F 5$ is also regulated by PmrA/B, as expected from its location in the $p m r F$ operon.

As the S. typhimurium pmrF operon is involved with $\mathrm{PmB}$ resistance, we tested our $S$. typhi strains for $\mathrm{PmB}$ resistance. The $S$. typhi Ty2 wild-type strain was approximately 10 -fold more sensitive to $\mathrm{PmB}$ than $S$. typhimurium C5 (data not shown), and the S. typhi PhoP $^{\mathrm{c}}$ (RMA1090) mutant had an increased resistance to PmB compared to the wild-type Ty2 strain (Fig. 5). The pqaB:: MudJ PhoP ${ }^{\mathrm{c}}$ (RMA2326) strain was more sensitive to $\mathrm{PmB}$ than $\mathrm{RMA} 1090\left(\mathrm{PhoP}^{\mathrm{c}}\right)$, indicating that the $S$. typhi pqaB gene is also involved with $\mathrm{PmB}$ resistance. The sensitivity of $p m r F$ and $p q a B$ mutants to $\mathrm{PmB}$ is consistent with these genes affecting the same pathway for LPS modifications (ORFs $1-7$, functions outlined in Fig. 4).

It has been suggested that since LPS is negatively charged and most antimicrobial peptides (including $\mathrm{PmB}$ and melittin) are cationic at physiological $\mathrm{pH}$, mutations which alter the phosphate content or LPS substitutions may change the negative charge of the LPS and therefore affect the ability of the cationic peptides to bind to the LPS (Groisman, 1994). An increase in both ethanolamine and 4-deoxyaminoarabinose substitution results in a lower surface negative charge of the lipid $\mathrm{A}$ and inner core parts of the LPS, and therefore give a greater resistance to cationic peptides (Helander et al., 1994). As both $S$. typhi and S. typhimurium $\mathrm{PhoP}^{\mathrm{c}}$ mutants have their $p q a / p a g$ genes constitutively up-regulated, this would explain why they have a higher resistance to antimicrobial agents such as $\mathrm{PmB}$, as seen for the $S$. typhi PhoP ${ }^{\mathrm{C}}$ (RMA1090) strain compared to the wildtype strain (Fig. 5), and for S. typhimurium (Gunn et al., 1998).
Compared to S. typhi, S. typhimurium strains have been previously shown to have an approximately 10 -fold higher resistance level to a number of antimicrobial agents (unpublished data; Baker et al., 1997). This higher level of resistance may be due to either different $p a g / p q a$ genes or greater/different modifications for $S$. typhimurium LPS compared to S. typhi. Modifications such as the 4-deoxyaminoarabinose and ethanolamine may be regulated/added to give a higher modification level in S. typhimurium than S. typhi. Alternatively there may be other modifications, as yet undetected, that may be different between the two Salmonella species, such that $S$. typhi LPS may have a naturally higher negative charge than S. typhimurium LPS. Our PMA-U937 assay may be sensitive enough to detect these differences in $S$. typhi strains but not $S$. typhimurium. This may explain why, unlike the S. typhi $\mathrm{PhoP}^{-}$mutant, the S. typhimurium $\mathrm{PhoP}^{-}$mutant was not limited in net growth in the PMA-U937 cells compared to the wild-type strain.

\section{Effects on Salmonella LPS}

The results mentioned above strongly indicate that $S$. typhi and S. typhimurium LPS may be different, although they have some of the same PhoP/Q- and PmrA/B-regulated lipid A modifications. We examined the LPS of S.typhi Ty2, PhoP ${ }^{-}$, PhoP $^{\mathrm{c}}$, pqaB:: MudJ and $p q a B:: \mathrm{MudJ} / \mathrm{PhoP}^{\mathrm{c}}$ on an SDS-PAGE gel, and the LPS of S. typhimurium C5 and $\mathrm{PhoP}^{-}$, $\mathrm{PhoP}^{\mathrm{c}}$ derivatives. Based on chemical analysis showing that $S$. typhimurium $\mathrm{PhoP}^{\mathrm{c}}$ LPS had shorter O-antigen chains (Guo et al., 1997), we expected to see a difference between the LPS of the $S$. typhimurium wild-type and its $\mathrm{PhoP}^{\mathrm{c}}$ derivative. As can be seen in Fig. 6, there was a remarkable difference between S. typhimurium C5 and PhoP $\mathrm{P}^{\mathrm{c}} \mathrm{LPS}$, with much shorter $\mathrm{O}$-antigen chains being evident for the $\mathrm{PhoP}^{\mathrm{c}}$ strain. This is in direct contrast to the $S$. typhi Ty 2, PhoP ${ }^{-}$and $\mathrm{PhoP}^{\mathrm{C}}$ strains, for which no difference in O-antigen chain length could be detected (Fig. 6). The lack of discrete high-molecular-mass bands is the only subtle difference seen between the S. typhi pqaB mutants (RMA2326 and RMA2356) and their wild-type (Ty2) and PhoP $^{\mathrm{C}}$ (RMA1090) counterparts. The LPS of strain RMA2356 also appeared to have fewer O-antigen chains. The LPS of both S. typhi Ty 2 and S. typhimurium C5 strains showed no dramatic differences compared to their $\mathrm{PhoP}^{-}$derivatives; this was reported previously for S. typhimurium wild-type and $\mathrm{PhoP}^{-}$strains by Galan $\&$ Curtiss (1989). Interestingly, the modal chain length of the LPS for $S$. typhi is much longer than that of the LPS of S. typhimurium. This suggests that they have different $w z z$ genes. We have been able to confirm this as we were unable to amplify the $S$. typhi wzz gene by PCR using $S$. typhimurium wzz gene-specific oligonucleotides (C. Daniels \& R. Morona, unpublished data), which suggests significant nucleotide differences of these two genes in S. typhi and S. typhimurium. The differences between $S$. typhi and S. typhimurium LPS described above correlate with differential susceptibility to $\mathrm{PmB}$, antimicrobial peptides and net growth in PMA-U937 cells. Given the importance of LPS in Salmonella 
virulence, these differences may impact on the relative virulence of Salmonella species in different hosts.

Currently, we are studying the structural modifications of LPS from $S$. typhi Ty2, $\mathrm{PhoP}^{-}, \mathrm{PhoP}^{\mathrm{c}}$ and pqaB::MudJ derivatives by mass spectrometry to confirm and extend the known differences between $S$. typhi and S. typhimurium LPS.

\section{ACKNOWLEDGEMENTS}

This study was funded by a Project Grant from the National Health and Medical Research Council of Australia. Mr Chris Murray of the Salmonella Reference Laboratory is thanked for serotyping our Salmonella strains.

\section{REFERENCES}

Alpuche-Aranda, C. M., Racoosin, E. L., Swanson, J. A. \& Miller, S. I. (1994). Salmonella stimulate macrophage macropinocytosis and persist within spacious phagosomes. J Exp Med 179, 601-608.

Alpuche-Aranda, C. M., Berthiaume, E. P., Mock, B., Swanson, J. A. \& Miller, S. I. (1995). Spacious phagosome formation within mouse macrophages correlates with Salmonella serotype pathogenicity and host susceptibility. Infect Immun 63, 4456-4462.

Altschul, S. F., Gish, W., Miller, W., Myers, E. W. \& Lipman, D. J. (1990). Basic local alignment search tool. J Mol Biol 215, 403-410.

Baker, S. J., Daniels, C. \& Morona, R. (1997). PhoP/Q regulated genes in Salmonella typhi identification of melittin sensitive mutants. Microb Pathog 22, 165-179.

Barrow, P. A., Huggins, M. B. \& Lovell, M. A. (1994). Host specificity of Salmonella infection in chickens and mice is expressed in vivo primarily at the level of the reticuloendothelial system. Infect Immun 62, 4602-4610.

Bastin, D. A., Lord, A. \& Verma, N. K. (1997). Cloning and analysis of the glucosyl transferase gene encoding type I antigen in Shigella flexneri. FEMS Microbiol Lett 156, 133-139.

Bearson, B. L., Wilson, L. \& Foster, J.W. (1998). A low pHinducible, PhoPQ-dependent acid tolerance response protects Salmonella typhimurium against inorganic acid stress. J Bacteriol 180, 2409-2417.

Behlau, I. \& Miller, S. I. (1993). A PhoP-repressed gene promotes Salmonella typhimurium invasion of epithelial cells. J Bacteriol $175,4475-4484$.

Buchmeier, N. A. \& Heffron, F. (1989). Intracellular survival of wild-type Salmonella typhimurium and macrophage-sensitive mutants in diverse populations of macrophages. Infect Immun 57, $1-7$.

Davis, R. W., Botstein, P. \& Roth, J. R. (1980). Advanced Bacterial Genetics; a Manual for Genetic Engineering. Cold Spring Harbor, NY: Cold Spring Harbor Laboratory.

Feingold, D. S. \& Barbar, G. A. (1990). Nucleotide sugars. In Carbohydrates, pp. 39-78. Edited by P. M. Dey. London: Academic Press.

Fields, P. I., Swanson, R. V., Haidaris, C. G. \& Heffron, F. (1986). Mutants of Salmonella typhimurium that cannot survive within the macrophage are avirulent. Proc Natl Acad Sci USA 83, 5189-5193.

Fields, P. I., Groisman, E. A. \& Heffron, F. (1989). A Salmonella locus that controls resistance to microbicidal proteins from phagocytic cells. Science 243, 1059-1062.

Galan, J. E. \& Curtiss, R. D. (1989). Virulence and vaccine potential of phoP mutants of Salmonella typhimurium. Microb Pathog 6 , 433-443.

Garcia Vescovi, E., Soncini, F. C. \& Groisman, E. A. (1996). $\mathrm{Mg}^{2+}$ as an extracellular signal: environmental regulation of Salmonella virulence. Cell 84, 165-174.

Groisman, E. A. (1994). How bacteria resist killing by hostdefense peptides. Trends Microbiol 15, 30-33.

Groisman, E. A. \& Saier, M. H., Jr (1990). Salmonella virulence: new clues to intramacrophage survival. Trends Biochem Sci 15, 30-33.

Groisman, E. A., Saier, M. H., Jr \& Ochman, H. (1992). Horizontal transfer of a phosphatase gene as evidence for mosaic structure of the Salmonella genome. EMBO J 11, 1309-1316.

Groisman, E. A., Kayser, J. \& Soncini, F. C. (1997). Regulation of polymyxin resistance and adaptation to low $-\mathrm{Mg}^{2+}$ environments. J Bacteriol 179, 7040-7045.

Gunn, J. S. \& Miller, S.I. (1996). PhoP-PhoQ activates transcription of PmrAB, encoding a two-component regulatory system involved in Salmonella typhimurium antimicrobial peptide resistance. J Bacteriol 178, 6857-6864.

Gunn, J. S., Lim, K. B., Krueger, J., Kim, K., Guo, L., Hackett, M. \& Miller, S. I. (1998). PmrA-PmrB-regulated genes necessary for 4aminoarabinose lipid A modification and polymyxin resistance. Mol Microbiol 27, 1171-1182.

Guo, L., Lim, K. B., Gunn, J. S., Bainbridge, B., Darveau, R. P., Hackett, M. \& Miller, S. I. (1997). Regulation of lipid A modifications by Salmonella typhimurium virulence genes $p h o P-p h o Q$. Science 276, 250-253.

Harris, P. \& Ralph, P. (1985). Human leukemic models of myelomonocytic development: a review of the HL-60 and U937 cell lines. J Leukoc Biol 37, 407-422.

Hass, R., Bartels, H., Topley, N., Hadam, M., Kohler, L., Goppelt Strube, M. \& Resch, K. (1989). TPA-induced differentiation and adhesion of U937 cells: changes in ultrastructure, cytoskeletal organization and expression of cell surface antigens. Eur J Cell Biol 48, 282-293.

Helander, I. M., Kilpelainen, I. \& Vaara, M. (1994). Increased substitution of phosphate groups in lipopolysaccharides and lipid A of the polymyxin-resistant pmrA mutants of Salmonella typhimurium: a 31P-NMR study. Mol Microbiol 11, 481-487.

Hitchcock, P. J. \& Brown, T. M. (1983). Morphological heterogeneity among Salmonella lipopolysaccharide chemotypes in silver-stained polyacrylamide gels. J Bacteriol 154, 269-277.

Hohmann, E. L., Oletta, C. A., Killeen, K. P. \& Miller, S. I. (1996a). phoP/phoQ-deleted Salmonella typhi (Ty800). is a safe and immunogenic single-dose typhoid fever vaccine in volunteers. $J$ Infect Dis 173, 1408-1414.

Hohmann, E. L., Oletta, C. A. \& Miller, S. I. (1996b). Evaluation of a $p h o P / p h o Q$-deleted, aroA-deleted live oral Salmonella typhi vaccine strain in human volunteers. Vaccine 14, 19-24.

Hone, D. M., Tacket, C. O., Harris, A. M., Kay, B., Losonsky, G. \& Levine, M. M. (1992). Evaluation in volunteers of a candidate live oral attenuated Salmonella typhi vector vaccine. J Clin Invest $\mathbf{9 0 ,}$ 412-420.

Huan, P. T., Bastin, D. A., Whittle, B. L., Lindberg, A. A. \& Verma, N. K. (1997a). Molecular characterization of the genes involved in $\mathrm{O}$-antigen modification, attachment, integration and excision in Shigella flexneri bacteriophage SfV. Gene 195, 217-227.

Huan, P. T., Whittle, B. L., Bastin, D. A., Lindberg, A. A. \& Verma, N. K. (1997b). Shigella flexneri type-specific antigen V: cloning, sequencing and characterization of the glucosyl transferase gene of temperate bacteriophage SfV. Gene 195, 207-216. 
Johnston, C., Pegues, D. A., Hueck, C. J., Lee, A. \& Miller, S. I. (1996). Transcriptional activation of Salmonella typhimurium invasion genes by a member of the phosphorylated responseregulator superfamily. Mol Microbiol 22, 715-727.

Kasahara, M., Nakata, A. \& Shinagawa, H. (1991). Molecular analysis of the Salmonella typhimurium phoN gene, which encodes nonspecific acid phosphatase. J Bacteriol 173, 6760-6765.

Mavris, M., Manning, P. A. \& Morona, R. (1997). Mechanism of bacteriophage SfII-mediated serotype conversion in Shigella flexneri. Mol Microbiol 26, 939-950.

Miller, S. I. (1991). PhoP/PhoQ: macrophage-specific modulators of Salmonella virulence? Mol Microbiol 5, 2073-2078.

Miller, S. I. \& Mekalanos, J. J. (1990). Constitutive expression of the phoP regulon attenuates Salmonella virulence and survival within macrophages. J Bacteriol 172, 2485-2490.

Miller, S. I., Kukral, A. M. \& Mekalanos, J. J. (1989). A twocomponent regulatory system ( $p h o P$ phoQ) controls Salmonella typhimurium virulence. Proc Natl Acad Sci USA 86, 5054-5058.

Miller, S. I., Hohmann, E. L. \& Pegues, D. A. (1995). Salmonella (including Salmonella typhi). In Principles and Practice of Infectious Diseases, pp. 2013-2033. Edited by G. L. Mandell, J. E. Bennett \& R. Dolen. New York: Churchill Livingstone.

Mills, S. D. \& Finlay, B. B. (1994). Comparison of Salmonella typhi and Salmonella typhimurium invasion, intracellular growth and localization in cultured human epithelial cells. Microb Pathog 17, 409-423.

Minta, J. O. \& Pambrun, L. (1985). In vitro induction of cytologic and functional differentiation of the immature human monocytelike cell line U-937 with phorbol myristate acetate. Am J Pathol $119,111-126$.

Monack, D. M., Raupach, B., Hromockyj, A. E. \& Falkow, S. (1996). Salmonella typhimurium invasion induces apoptosis in infected macrophages. Proc Natl Acad Sci USA 93, 9833-9838.

Moreno, E., Mayer, H. \& Moriyon, I. (1987). Characterization of a native polysaccharide hapten from Brucella melitensis. Infect Immun 55, 2850-2853.

Morona, R., Brown, M. H., Yeadon, J., Heuzenroeder, M. W. \& Manning, P. A. (1991). Effect of lipopolysaccharide core synthesis mutations on the production of Vibrio cholerae O-antigen in Escherichia coli K-12. FEMS Microbiol Lett 66, 279-285.

Morona, R., van den Bosch, L. \& Manning, P. A. (1995). Molecular, genetic and topological characterization of $\mathrm{O}$-antigen chain length regulation in Shigella flexneri. J Bacteriol 177, 1059-1068.

Ochman, H., Gerber, A. S. \& Hartl, D. L. (1988). Genetic applications of an inverse polymerase chain reaction. Genetics 120, 621-623.

Pedrinaci, S., Huelin, C., Patarroyo, M., Ruiz Cabello, F. \& Garrido, F. (1989). Studies on CD11a and CD18 molecules with two new monoclonal antibodies: differential myelomonocytic antigen expression of PMA treated HL60 and U937 cell lines. Hybridoma 8, 13-23.

Pegues, D. A., Hantman, M. J., Behlau, I. \& Miller, S. I. (1995). PhoP/PhoQ transcriptional repression of Salmonella typhimurium invasion genes: evidence for a role in protein secretion. Mol Microbiol 17, 169-181.

Porter, E. M., van Dam, E., Valore, E. V. \& Ganz, T. (1997). Broadspectrum antimicrobial activity of human intestinal defensin 5 . Infect Immun 65, 2396-2401.

Pulkkinen, W. S. \& Miller, S. I. (1991). A Salmonella typhimurium virulence protein is similar to a Yersinia enterocolitica invasion protein and a bacteriophage lambda outer membrane protein. $J$ Bacteriol 173, 86-93.

Selsted, M. E., Miller, S. I., Henschen, A. H. \& Ouellette, A. J. (1992). Enteric defensins: antibiotic peptide components of intestinal host defense. J Cell Biol 118, 929-936.

Shyamala, V. \& Ames, G. F. (1993). Single specific primerpolymerase chain reaction (SSP-PCR) and genome walking. In PCR Protocols: Current Methods and Applications, pp. 339-348. Edited by B. A. White. Totowa: Humana Press.

Soncini, F. C. \& Groisman, E. A. (1996). Two-component regulatory systems can interact to process multiple environmental signals. J Bacteriol 178, 6796-6801.

Stroeher, U. H., Karageorgos, L. E., Brown, M. H., Morona, R. \& Manning, P. A. (1995). A putative pathway for perosamine biosynthesis is the first function encoded within the rfb region of Vibrio cholerae O1. Gene 166, 33-42.

Sundstrom, C. \& Nilsson, K. (1976). Establishment and characterization of a human histiocytic lymphoma cell line (U-937). Int $J$ Cancer 17, 565-577.

Tenhaken, R. \& Thulke, O. (1996). Cloning of an enzyme that synthesizes a key nucleotide-sugar precursor of hemicellulose biosynthesis from soybean: UDP-glucose dehydrogenase. Plant Physiol 112, 1127-1134.

Verma, N. K., Verma, D. J., Huan, P. T. \& Lindberg, A. A. (1993). Cloning and sequencing of the glucosyl transferase-encoding gene from converting bacteriophage X (SFX) of Shigella flexneri. Gene 129, 99-101.

Vescovi, E. G., Sancini, F. C. \& Groisman, E. A. (1994). The role of phoP/Q regulon in Salmonella virulence. Res Microbiol 145, 473-480.

Valdivia, R. H. \& Falkow, S. (1996). Bacterial genetics by flow cytometry: rapid isolation of Salmonella typhimurium acidinducible promoters by differential fluorescence induction. $\mathrm{Mol}$ Microbiol 22, 367-378.

Received 27 July 1998; revised 29 September 1998; accepted 3 November 1998. 